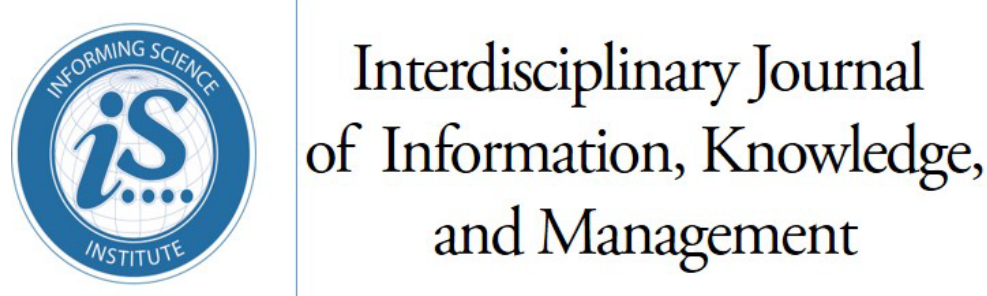

An Official Publication

of the Informing Science Institute

InformingScience.org

IJIKM.org

Volume 14, 2019

\title{
EFFECTS OF ONLINE ADVOCACY BANNERS ON Customers after Abandoning Products in Online SHOPPING CARTS
}

$\begin{array}{lll}\text { Hsiaoping Yeh* } & \begin{array}{l}\text { National Kaohsiung University of } \\ \text { Science and Technology, Kaohsiung, } \\ \text { Taiwan }\end{array} & \text { hpyeh2000@nkust.edu.tw } \\ \text { Fenghung Kuo } & \begin{array}{l}\text { National Kaohsiung University of } \\ \text { Science and Technology, Kaohsiung, } \\ \text { Taiwan }\end{array} & \\ * \text { Corresponding author } & \end{array}$

ABSTRACT

Aim/Purpose This study empirically analyzed and examined the effectiveness of the online advocacy banners on customers' reactions to make replacements with the similar products in their shopping carts.

Background When a product in a shopping cart is removed, it might be put back into the cart again during the same purchase or it may be bought in the future. Otherwise, it might be abandoned and replaced with a similar item based on the customer's enquiry list or on the recommendation of banners. There is a lack of understanding of this phenomenon in the existing literature, pointing to the need for this study.

Methodology With a database from a Taiwanese e-retailer, data were the tracks of empirical webpage clickstreams. The used data for analyses were particularly that the products were purchased again or replaced with the similar ones upon the advocacy banners being shown when they were removed from customers' shopping carts. Few pre-defined Apriori rules as well as similarity algorithm, Jaccard index, were applied to derive the effectiveness.

Contribution This study addressed a measurement challenge by leveraging the information from clickstream data - particularly clickstream data behavior. These data are most useful to observe the real-time behavior of consumers on websites and also are applied to studying click-through behavior, but not click-through rates,

Accepting Editor Ewa Wanda Ziemba | Received: December 3, 2018| Revised: March 4, March 11, April 7, 2019 | Accepted: April 9, 2019.

Cite as: Yeh, H., \& Kuo, F. (2019). Effects of advocacy banners after abandoning products in online shopping carts. Interdisciplinary Journal of Information, Knowledge, and Management, 14, 165-181. https://doi.org/10.28945/4310

(CC BY-NC 4.0) This article is licensed to you under a Creative Commons Attribution-NonCommercial 4.0 International License. When you copy and redistribute this paper in full or in part, you need to provide proper attribution to it to ensure that others can later locate this work (and to ensure that others do not accuse you of plagiarism). You may (and we encourage you to) adapt, remix, transform, and build upon the material for any non-commercial purposes. This license does not permit you to use this material for commercial purposes. 
Findings

Recommendations for Practitioners

Recommendations for Researchers

Impact on Society

Future Research

Keywords for web banners. The study develops a new methodology to aid advertisers in evaluating the effectiveness of their banner campaign.

The recommending/advocating titles of "you probably are interested" and "the most viewed" are not significantly effective on saving back customers' removed products or repurchasing similar items. For the banners entitled "most buy", "the most viewed" might only show popularity of the items, but is not enough to convince them to buy. At the current stage on the host website, customers may either not trust in the host e-retailer or in such mechanism. Additionally, the advocating/recommending banners only are effective on the same customer visits and their effects fade over time. As time passes, customers' impressions of these banners may become vague.

One managerial implication is more effective adoption of advoca-

$\mathrm{cy} /$ recommendation banners on e-retailing websites. Another managerial implication is the evaluation of the advocacy/recommendation banners. By using a data mining technique to find the association between removed products and restored ones in e-shoppers' shopping carts, the approach and findings of this study, which are important for e-retailing marketers, reflect the connection between the usage of banners and the personalized purchase changes in an individual customer's shopping cart.

This study addressed a new measurement which challenges to leverage the information from clickstream data instead of click-through rates - particularly retailing webpages browsing behavior. These data are most useful to observe the real-time behavior of consumers on websites and also are applied to studying click-through behavior.

Personalization has become an important technique that allows businesses to improve both sales and service relationships with their online customers. This personalization gives e-marketers the ability to deliver real effectiveness in the use of banners.

The effectiveness is time- and case-sensible. Business practitioners and academic researchers are encouraged to apply the mining methodology to longevity studies, specific marketing campaigns of advertising and personal recommendations, and any further recommendation algorithms.

recommendation banner, product similarity, association rule

\section{INTRODUCTION}

For online retailers, they might all expect transactions with customers who select products, put them in shopping carts, and check out. However, for various reasons, before the checking-out, some products are removed from the shopping carts. Some items may be put back into the carts again and checked out, or they may be replaced by similar ones at the checkout point. These items or similar ones may be purchased some other time, or may be totally abandoned. Abandoned shopping carts are the driving force for personal retargeting (Goodman, 2014), as is an understanding of the reasons for removal of products from the carts. Although reasons for the abandoning shopping carts or the removal of products are multifaceted, the most immediate encouragement for the customers to put back the item (or a similar one) is personalized advocacy, e.g., recommender systems, inference, or referral programs such as social causes (such as Word of Mouth, WOM), individual effects (personal search), marketing communications (East, Lomax, \& Narain,, 2001), or incentives given by retailers to the customers (Biyalogorsky, Gerstner, \& Libai, 2001). Trigger advocacy to the customers while 
they are making purchasing decisions include four important areas (Constantinidea, 2008): promotions (e.g., advertising), value (pricing and deals), experience (usage or product trial), and product/service (e.g., quality, innovations, features). Companies should use their websites as a platform to advocate their products to their customers. Nowadays, online retailers often adopt banners as recommendations and/or advocacies for their shoppers on the product pages that the shoppers are viewing, such as "you might also be interested", "others also bought", "the hot items", "most viewed", or "limited time sale".

Studies estimate that approximately $60 \%-75 \%$ of all shopping carts are abandoned before purchases are made and over a half of these shopping carts are abandoned due to competing sites (Gold, 2007). The phenomenon is especially pertinent in the context of e-commerce. Although "product removal from the shopping cart" seems to be telling a different story of customer behavior, it reflects particular behavior - "conversion" - and occurs right after the customer has decided to purchase the products but just before the purchase is completed, resulting in a switch to some similar but competing product. Marketing managers make enormous efforts to sell their products and to provide services for their customers. Their marketing activities are focused on ensuring that the customers choose their products from a wide range of competing products. The Internet has provided a platform for customers and marketers to have more interaction, making it possible for E-businesses to customize service and cater to customers' individual requirements. This study ascertains the importance for e-retailing managers (e.g., product, marketing, and retailing) to be able to deliver these customer services in the online environment and also helps researchers to understand the factors leading to this "product removal" by customers.

When a product in a shopping cart is removed, it might be put back into the cart again during the same purchase, or it may be bought in the future. Otherwise, it might be abandoned and replaced with a similar item based on the customer's enquiry list or on the recommendation of banners. There is a lack of understanding of this phenomenon in the existing literature, pointing to the need for this study. The aim of the study is to empirically analyze and examine the advocating effectiveness of customers' reactions to the various online banners and recommendations, placed by the e-retailer who runs the online shopping platform, and to study e-shoppers' succeeding decisions after they have removed a product from their shopping carts. The study observes the products in customers' shopping carts and the banners about these items on the webpage during three purchase sessions observed in this study, and combines the association rule technique with pre-defined Apriori association rules and the similarity algorithm, Jaccard index, to achieve the goals of the study.

In the next section studied and investigated effects of banner ads as well as contemporary recommenders for online retail businesses are reviewed and the description of the data mining technique, Association Rule (AR), used in this study follows. In the third section, operations of AR mining to examine the effects on abandoned products in shopping carts are elaborated. Effectiveness of advocacies on saving up abandoned products or replacements with similar products are described in the fourth section and sections of discussion and conclusion follow.

\section{RELATED WORK AND LITERATURE REVIEW}

The Internet can be referred to as a pull medium because customers choose the content they view. Research has shown that some forms of online advertising to be effective in influencing customer behavior. Goh and Chintagunta (2006) suggested that exposure to web banner ads increases the probability of customer purchase. A web banner is a type of graphic image that appears on a webpage and when users click on that image, they are redirected to another webpage that provides information about the product shown in the graphic image. In 2010, banner ads generated revenue of $\$ 6.2$ billion in the US alone, representing a little over a quarter of the online advertising revenue that year (Interactive Advertising Bureau [IAB], 2011). In the world of e-commerce, the usage of banners is generally represented as referrals in an attempt to point customers to other sites that also meet their individual proclivities, typically through personalization. Some of these referral programs, oper- 
ated by marketers, are called as affinity marketing. Affinity marketing is playing an increasingly important role in e-commerce in increasing site visibility, driving traffic and boosting sales (Bloom, Hoeffler, Keller, \& Basurto Meza, 2006).

Lohtia, Donthu, and Hershberger (2003) examined banner ads and found that that click-through rates on banners, even the incentives ones, such as free offers, are getting lower. These authors argued that customers avoid clicking on banner ads when they are engaged in goal-directed navigation, but that these ads do improve brand attitude. Ehrenberg, Barnard, Kennedy, and Bloom (2002) explained that banner ads create brand image that causes the brand to seem more familiar and enhance the customers' consideration and choice. Therefore, banner ads are not viewed as annoying features and their exposure significantly increases the likelihood of a purchase (Manchanda, Dube, Goh, \& Chintagunta, 2006; Yeu, Yoon, Taylor, \& Lee, 2013). There are also some developing positive views about Internet banner ads and their potential. For example, as online shoppers browse a web store, it would be common for them to move quickly from an information search to a look at alternatives by comparing the price and features of all of the alternatives. Studies have shown that if customers surfing a website see a banner that they view as relevant, they may take immediate action, such as clicking and then making a purchase (Courbet, Fourquet-Courbet, \& Vanhuele, 2007; Manchanda et al., 2006). Further, the determination of a customer's final decision on an online purchase involves a comparison of alternatives in order to mediate the perceived need-state of the customer (Volk, 2001). Through clicking on banners, online shoppers often alter their decisions rapidly (Butler \& Peppard, 1998). While traditional media face problems related to clutters and segments, the advocacy banners provide an opportunity to stand out and deliver messages that enhance the relevance of a product to customers (Nasco \& Bruner, 2008; Pagnani, 2004). Given the potential advantages of banner ads with behavioral targeting, it is important for researchers to explore the contexts in which customers are attentive to web banners. This can provide retailers with an opportunity to customize the message and gain customers' attention and thus, to enhance sales.

The causes leading to change in customer preferences and demands are recommendations, purchase advocacy, or referral systems. Recommendation is clearly one of the important influences on customers' purchasing decisions (Zahir, 2002). Rosen and Olshavsky (1987) found that recommendations can speed up people's decisions. East and his colleagues (East et al., 2001) found that over 30\% of customers switched their choice due to recommendations. The use of online recommender systems on e-retailing sites is becoming more common as marketers recognize their potential to improve both their own operations and customers' shopping experiences and behaviors. Recommender systems are defined as information sources that provide customers with information that is very personalized (Ansari, Essegaier, \& Kohli, 2000). Past research has explored recommender systems based on software generated algorithms that aggregate different types of information provided by a company, by an independent party, or by customers (Aggarwal \& Vaidyanathan, 2005; Ochi, Rao, Takayama, \& Nass, 2010; Senecal \& Nantel, 2004). While the use of recommendations is growing rapidly, the specific characteristics that customers want from these services have yet to be thoroughly researched (Aljukhadar \& Senecal, 2011). This is especially important in the context of recommendations. In order to avoid information overload, they must efficiently and effectively aid customer decision-making rather than overwhelm them with additional and irrelevant information (Haubl \& Murray, 2006). By designing relevant and easy-to-use recommendations that include only the targeted features that the customers want, marketers can improve customer satisfaction and generate more sales.

A growing number of consumers find value in recommendations, so marketers have little choice but no incorporate them into their online stores (Ochi et al., 2010; Zahir 2002). Recommender systems in the marketing literature are mostly referred to as similar to WOM. It has been suggested by researchers that trustworthy and reliable recommendations (but not fully directed to customers' actions in terms of placing orders) come from independent sources rather than from the retailers themselves (Lepkowska-White, 2013; Weathers, Sharma, \& Wood, 2007; West et al., 1999). In addition, some 
studies have indicated that the fit between the context of the recommendation and product characteristics is important (Aggarwal \& Vaidyanathan, 2005; Ochi et al., 2010). Therefore, the effects of product types on customers' responses to such recommendations on the actual purchases should be examined, focusing recommendations that are based on a variety of information coming from the host retailer. In this way e-retailers can personalize a relationship with their customers, based on their responses to recommendations coming directly from the host retailers. Nowadays, in addition to banner ads posted from other companies, usually promoting different product types, e-commerce retailers are adopting banners for recommendations titled "best buy", "hot items", or "others also bought" on the pages the customers are viewing. However, customers' purchasing decisions are not only affected by recommendations. In fact, product characteristics also provide important information for customers to evaluate. Indeed, Aggarwal and Vaidyanathan (2005) found that customers prefer recommendations that match their preferences for product features rather than recommendations that are generated from a variety of other sources. However, Ochi et al. (2010) derived the opposite result, finding that customers prefer the latter over the former. Thus, this study examined the effects of recommendations with different contexts coming directly from the host retailers for the removal of a product from the shopping cart, and then put back in the shopping cart or replaced with a similar product that has the same or similar features.

The effectiveness of online banners is difficult to evaluate (Rutz \& Bucklin, 2012). Two standard metrics, page views and click-through rates, are both problematic (DoubleClick, 2002). Researchers suggest that click-through rate might be a poor measure of the performance of banner ads (Dreze \& Hussherr, 2003). Therefore, this study provides a different approach to the examination of the effects of online banners. Nowadays, data systems have been widely adopted in businesses and the massive data collected from business transactions have made entrepreneurs realize that they can use this data to support their business decision making (Clifford, 2008). Therefore, Knowledge Discovery in Database (KDD) has become an essential concept for the extraction of useful and valid knowledge from data. Fields of data are usually dependent, yet recessive. The processes and algorithms of data mining are used to find patterns that describe underlying relationships in the data. If such dependent and recessive patterns are discovered with data mining techniques, the results are very useful for businesses and industries in making important decisions. Association Rule (AR) mining (Piatetsky-Shapiro, 1991) looks for frequently occurring patterns in the data and is often used for market basket analysis. The famous result is the diaper-beer rule in baskets. The results from market basket analysis contribute to better shelf management, good supply, and more effective marketing for retailers.

Data similarity is basically the grouping of a set of data with a predefined class attribute. For example, a set of commodities can be clustered into a set of classes and such clustering facilitates the formation of a set of rules for organizations so as to observe into a hierarchy of classes that group similar events together. Mining data for similarity enables users to replace a set of objects within a group with a standard or simplified object with a reasonable choice of subset of features, while still ensuring that the homogeneity with respect to the initial classification and the information about the set of objects is still kept (Zagoruiko, Borisova, Kutnenko, \& Dyubanov, 2013).

There are many types of AR mining techniques, grouped in different contexts of rule elements, such as in values (e.g., Boolean AR or quantitative AR), in dimensions (single and multi-dimension), in levels of data concepts (e.g., "13 inches monitor" is grouped in the higher-level "monitor") and in other AR extensions (Han \& Kamber, 2001). Basically, all AR mining techniques are rooted in Apriori (Agrawal, Imielinski, \& Swami, 1993). Apriori, developed by Agrawal and Srikant (1994), is an algorithm for mining ARs over transactional data. Also renowned as a market basket analysis, Apriori is used to find degree of association between two or more than two items in a shopping basket. Based on Mining data by Apriori has been currently applied in financial services, such as finding the important factors affecting customer payment of debt loans (Theresia \& Noranita, 2012), on telecommunication, such as identifying individual customer paid mobile service interests (Yao \& Shu, 2009), 
and on web safety, such as web monitoring to detect illegal or suspicious intrusions (Lee, Salvatore, \& Kui, 2002). In the retailing applications, Han, Pei, \& Yin (2000), Lawrence, Almasi, Kotlyar, Viveros, \& Duri (2001), and Yeh (2014) have testified that AR mining shopping basket data is able to effectively predict personalized shopping behavior. Kim (2002) also adopted Apriori rule mining to discover the factors affecting customers' trust in e-commerce. Recently, AR applications on recommender systems (e.g., Joshua et al. (2016) for personal books recommendation, Osadchiy, Poliakov, Olivier, Rowland, \& Foster (2019) for personal diet recommendation, Varzaneh, Neysiani, Ziafat, \& Soltani (2018) for retailing purchases recommendation) show AR's trendy for advancing results of recommender systems.

An AR with high support and confidence values is called a strong (or interesting) rule and is potentially useful for a system. The support value indicates the frequency of the occurring patterns in a rule, and the confidence one denotes the strength of this implication. Since the number of different items in basket may be large, a set of frequent item sets (i.e., items often purchased) is first derived by adopting a minimum support rule. Strong ARs are then discovered, with the rules' confidences greater than a minimum confidence rule. That is, ARs are extracted for system use when their values of support and confidence are greater than the thresholds of minimum support and minimum confidence. Other than support and confidence values, which are objective measures, many other subjective and objective measures are proposed to derive strong ARs (Geng \& Hamilton (2006) summarized 38 measures), or the valuable rules determined by visualization procedures (Klemettinen, Mannila, Ronkainen, Toivonen, \& Verkamo, 1994). Subjective measures are based on the background of the problem, the knowledge of the domain, and the expectation of the experts. They are not represented by strict mathematical formulae because of the variance of knowledge, requirement and environment. On the other hand, objective measures are designed to evaluate the generality and reliability of the ARs. It is generally accepted that there is no single measure that is perfect and applicable to all problems. Usually different ones are complementary and can be applied at different applications or phases for matching the properties of the particular problem (Geng \& Hamilton, 2006; Tan, Kumar, \& Srivastava, 2002; Zhang, 2009).

This study identifies the association relationships of a consumer's reaction to the advocacy and recommending banners of products abandoned in the shopping cart and being put back or replaced with a similar product. To represent the ARs of the attributes of consumer-related fields, the Apriori algorithm was used. The Apriori algorithm is one of the efficient algorithms that restricts the search space and checks a subset of ARs without missing important rules (Kim, 2002). Since the focus of this study was not on performance optimization, the Apriori algorithm was chosen for the reason that it is a well-established, commonly used, and well-studied algorithm.

\section{METHODOLOGY}

The purpose of this study was to discover the effects of advocacy/recommendation banners appearing on a product webpage leading to the customers' purchase conversion to recommended products which have similar functions and/or features. The raw data, used in this study was collected from January 2013 to June 2014 and stems from aggregations of members' online shopping routes, (note that this does not include the POS (i.e., orders) data), from a Taiwan e-retailing site. The retailer prefers to remain anonymous, and is denoted as ESHOP.com. The data coding scheme for the analyses follow four steps, initiating when a product is removed from a shopping cart:

(1) Searching products removed from the shopping cart;

A data point is created, for a certain ESHOP.com member when a removal product (denoted as A) is taken out of this member's shopping cart during a certain visit and one of the following situations subsequently happens:

i. A will be returned to the basket at the same visit;

ii. a similar product to A will be put into the basket at the same visit; 
iii. A will be in the basket at the next visit;

iv. a similar product to $\mathrm{A}$ will be put in at the next visit;

v. A will be in the basket at the next visit;

vi. a similar product to $A$ will be at the next visit;

vii. A will be in the basket at the third visit;

viii. The similar product to A will be put in at the third visit.

This study does not consider a situation in which A or its similarity product appears at members' further later visits (i.e., later than the third one).

(2) Deriving the removal of similar products on ESHOP.com;

Data similarity is basically the grouping of a set of data without a predefined class attribute. For example, a set of commodity objects can be first clustered into a set of classes and then a set of rules can be derived based on such a classification. Such clustering facilitates the formation of a taxonomy, which means the organization of the observations into a hierarchy of classes that group similar events together. Mining data for similarity enables users to replace a set of objects within a group with a standard or simplified object with a reasonable choice of subset of features, while still ensuring that the homogeneity with respect to the initial classification and the information about the set of objects is still kept.

Classification of products in terms of the physical functions and features is applied. In this study, a list of products that are similarities of an item was built with an approach using the Jaccard similarity index. The Jacaard (or Tanimoto) index, also known as the Jaccard similarity coefficient, originated in the early 20th century by the botanist Paul Jaccard (Jaccard, 2013), is used to understand the similarity of data sets. Mathematically, it is defined as the intersection of two data sets divided by the union of the same data sets (Eguia, Lozano, Racero, \& Guerrero, 2011). The Jaccard coefficient is defined as:

$$
J(X, Y)=\frac{|X \cap Y|}{|X \cup Y|}, 0 \leq J(X, Y) \leq 1
$$

If $\mathrm{X}$ and $\mathrm{Y}$ are both empty, $\mathrm{J}(\mathrm{X}, \mathrm{Y})$ is defined as 1.

For cases with binary attributes, given two objects $\mathrm{X}$ and $\mathrm{Y}$ and the $\mathrm{n}$ attributes used by the system, the Jaccard coefficient is a useful measure of that $\mathrm{X}$ and $\mathrm{Y}$ share with their attributes. The total numbers of each combination of attributes for both $\mathrm{X}$ and $\mathrm{Y}$ is specified as follows:

[1] M11 represents the total number of attributes where $\mathrm{X}$ and $\mathrm{Y}$ both match;

[2] M01 represents the total number of attributes where $\mathrm{X}$ does not match but $\mathrm{Y}$ does;

[3] M10 represents the total number of attributes where $\mathrm{X}$ matches but $\mathrm{Y}$ does not;

[4] M00 represents the total number of attributes where neither X nor Y matches.

Each attribute must fall into one of these four categories, meaning that

$$
\mathrm{M} 11+\mathrm{M} 01+\mathrm{M} 10+\mathrm{M} 00=\mathrm{n} .
$$

The Jaccard similarity coefficient is calculated wit $J=\frac{\mathrm{M}_{11}}{\mathrm{M}_{01}+\mathrm{M}_{10}+\mathrm{M}_{11}}$.

Hence, to derive the products that are similarities of A with the Jaccard index, the attributes used in this study were keywords in "product title" (limited to 2, and excluding products' brand names), keywords in "product description" (limited in 2), "product category", "product chapter", "product code", and "product sub code". There were 8 attributes used in this study to calculate the Jaccard similarity coefficient. The threshold value is set at 0.5 , meaning that the coefficient value should be greater than 0.5 for $\mathrm{A}$ and products similar to A's. 
(3) Calculating the likelihood of the product (or similar products) being returned (or put) into the shopping cart;

The ARs are pre-defined since this study only focused on the association relationship of A or any of the similarities of A being (re)considered by a customer after A was removed from the shopping cart, denoted as $\overleftarrow{\mathrm{A}}$. That is, all the ARs concerned in this study are:

(a) $\overleftarrow{\mathrm{A}} \rightarrow \mathrm{A}$ for the subsequence (i) of the step (1);

(b) $\overline{\mathrm{A}} \rightarrow \mathrm{s}(\mathrm{A})$ for the subsequence (ii) of the step (1), s(A) is denoted as the product set of the similarities of $\mathrm{A}$;

(c) $\overleftarrow{\mathrm{A}} \stackrel{1}{\rightarrow} \mathrm{A}$ for the subsequence (iii) of the step (1);

(d) $\overleftarrow{\mathrm{A}} \stackrel{1}{\rightarrow} \mathrm{s}(\mathrm{A})$ for the subsequence (iv) of the step (1);

(e) $\overleftarrow{\mathrm{A}} \stackrel{2}{\rightarrow} \mathrm{A}$ for the subsequence (v) of the step (1);

(f) $\overleftarrow{\mathrm{A}} \stackrel{2}{\rightarrow} \mathrm{s}(\mathrm{A})$ for the subsequence (vi) of the step (1);

(g) $\overleftarrow{\mathrm{A}} \stackrel{3}{\rightarrow} \mathrm{A}$ for the subsequence (vii) of the step (1);

(h) $\overleftarrow{\mathrm{A}} \stackrel{3}{\rightarrow} \mathrm{s}(\mathrm{A})$ for the subsequence (viii) of the step (1).

The likelihood of $\mathrm{A}$ or $\mathrm{s}(\mathrm{A})$ appearing in the shopping cart, whether at the current visit or the following visits after $A$ was removed, is measured with the confidence values of the above pre-defined ARs. Taking the AR $\overleftarrow{A} \rightarrow A$, for example, the confidence value is defined as:

$$
\operatorname{confidence}(\overline{\mathrm{A}} \rightarrow \mathrm{A})=\frac{\sum(\overline{\mathrm{A} \cup \mathrm{A})}}{\sum(\overline{\mathrm{A}})}=\mathrm{p}(\mathrm{A} \mid \overline{\mathrm{A}}) \text {. }
$$

$\sum(\overline{\mathrm{A}})$ denotes the total times of $\overline{\mathrm{A}}$ occurring in the data period for a certain member and $\sum(\overline{\mathrm{A}} \cup \mathrm{A})$ means the total number of times of $\overleftarrow{\mathrm{A}}$ and $\mathrm{A}$ occurs in the data period.

The confidence value is originally defined as two items appearing together at the same transaction (Agrawal et al., 1993). However, for the particular application in this study, $\sum(\overline{\mathrm{A}} \cup \mathrm{A})$ in cases (c) (h), to fit in the Apriori algorithm, was based on the occurrence of $\overleftarrow{A}$, assuming that $\overleftarrow{A}$ and $A$ appeared in the same transaction.

(4) Recording a data;

Along with the confidence value of all pre-defined ARs, if applicable, and the rule type (i.e., one of (a) $\sim(h)$ ), each data record was created with columns of this member's demography (including age, gender, and CPI (Consumer Price Index) of her/his living area), her/his average transaction frequency, yearly average expenditure, and product features of A (or s(A)) (including product category, chapter, code, sub code, price level (in three levels of upper, medium, and lower) under the same product group on ESHOP.com (product brand, product title, and product description) as well as whether the advocacy and recommendation banners containing A (or s(A), according to the rule type) appear on the $\overline{\mathrm{A}}$ 's webpage. This advocacy/recommendation information was on the banners entitled "the most buy", "others also buy", "you probably are interested", "limited time sale", "discount", and "the most viewed". Table 1 summarizes the product posting criteria on the ESHOP.com on the banners. 
Table 1. Product posting criteria on ESHOP.com

\begin{tabular}{|l|l|}
\hline BANNER CAPTION & DEFINITION \\
\hline The most buy & $\begin{array}{l}\text { For the same product category, the analytical results, only top 10 } \\
\text { items, from the recent one month orders on ESHOP.com }\end{array}$ \\
\hline Others also buy & $\begin{array}{l}\text { The analytical results, only top } 10 \text { items appearing in the same order. } \\
\text { 1a. For members, the viewed, but not been ordered in one month, } \\
\text { items by the login members. } \\
\text { 1b. For guest visitors, the viewed, but not been orders in one month, } \\
\text { items on the Internet hooked IP basis. } \\
\text { 2. For the same product category, the items whose prices are within } \\
\text { the range in less 20\% greater than that of the target item (for the up- } \\
\text { selling purpose). } \\
\text { 3. The accessory, appendage, and/or subordinate items (for the cross- } \\
\text { selling purpose) }\end{array}$ \\
\hline Limited time sale & $\begin{array}{l}\text { For the same product category, the current top } 10 \text { items with "limited } \\
\text { time sale". }\end{array}$ \\
\hline Discount & $\begin{array}{l}\text { For the same product category, the current top } 10 \text { items with the most } \\
\text { discounts. }\end{array}$ \\
\hline The most viewed & $\begin{array}{l}\text { For the same product category, the analytical results, only top 10 } \\
\text { items, from the recent one month items viewed by all visitors. }\end{array}$ \\
\hline
\end{tabular}

\section{FINDINGS}

Among the dataset on the ESHOP.com from January 2013 to June 2014, 89\% of visits of ESHOP.com members are adequate for the study analyses. The pre-defined ARs searching and their confidence values were derived with a self-coded $\mathrm{C}$ program. The program to obtain similar products is the modification of an open source code.

\section{INFLUENCES ON PRODUCTS (OR SIMILARITIES) BEING PUT BACKINTO BASKET}

The results of all stepwise multi-regression analyses are shown in Table 2. For all pre-defined ARs, the significant factors affecting the confidence values are genders of customers, price levels of products within the same product group, and the advocacy/recommendation banners entitled "others also buy", "most buy", "limited time sale", and "discount". However, brand name, members' CPIs in their living areas, and personal shopping habits in terms of shopping frequency and yearly expenditure are not significant influencing factors. 
Table 2. Factors affecting all pre-defined ARs

\begin{tabular}{|c|c|c|c|c|c|c|c|c|c|c|}
\hline \multirow[b]{2}{*}{ RULE } & \multirow[b]{2}{*}{$\mathrm{R}$} & \multirow[b]{2}{*}{$\mathrm{F}$} & \multirow[b]{2}{*}{$\mathrm{p}$} & \multicolumn{7}{|c|}{ STANDARDIZED COEFFICIENT } \\
\hline & & & & $\begin{array}{l}\text { CON- } \\
\text { STANT }\end{array}$ & $\begin{array}{l}\text { GEN } \\
\text { DER }\end{array}$ & $\begin{array}{l}\text { PRICE } \\
\text { LEVEL }\end{array}$ & $\begin{array}{l}\text { OTHERS } \\
\text { ALSO BUY }\end{array}$ & $\begin{array}{l}\text { MOST } \\
\text { BUY }\end{array}$ & $\begin{array}{l}\text { LIMITED } \\
\text { TIME SALE }\end{array}$ & $\begin{array}{l}\text { DIS- } \\
\text { COUN } \\
T\end{array}$ \\
\hline For all & .39 & 246.78 & .00 & -.34 & .07 & .05 & .07 & .09 & .08 & .03 \\
\hline$\overline{\mathrm{A}} \rightarrow \mathrm{A}$ & .93 & 1126.72 & .00 & -.72 & .17 & .10 & .20 & .09 & .12 & .04 \\
\hline$\overleftarrow{\mathrm{A}} \rightarrow \mathrm{s}(\mathrm{A})$ & .90 & 750.52 & .00 & -.73 & .12 & .13 & .20 & .17 & .12 & .04 \\
\hline$\overleftarrow{\mathrm{A}} \stackrel{1}{\rightarrow} \mathrm{A}$ & .62 & 287.03 & .00 & -.49 & .22 & .07 & .02 & .14 & .15 & .02 \\
\hline$\overleftarrow{\mathrm{A}} \stackrel{1}{\rightarrow} \mathrm{s}(\mathrm{A})$ & .93 & 1058.10 & .00 & -.36 & .04 & .07 & .03 & .12 & .12 & .04 \\
\hline$\overleftarrow{\mathrm{A}} \stackrel{2}{\rightarrow} \mathrm{A}$ & .68 & 152.31 & .00 & -.25 & .028 & .03 & .05 & .13 & .07 & .02 \\
\hline$\overleftarrow{\mathrm{A}} \stackrel{2}{\rightarrow} \mathrm{s}(\mathrm{A})$ & .83 & 387.38 & .00 & -.16 & .046 & .03 & .01 & .03 & .05 & .04 \\
\hline$\overleftarrow{\mathrm{A}} \stackrel{3}{\rightarrow} \mathrm{A}$ & .56 & 81.13 & .00 & -.03 & .00 & .00 & .00 & .00 & .00 & .00 \\
\hline$\overline{\mathrm{A}} \stackrel{3}{\rightarrow} \mathrm{s}(\mathrm{A})$ & .53 & 67.51 & .00 & -.01 & .00 & .00 & .00 & .00 & .00 & .00 \\
\hline
\end{tabular}

Since the products marked with "others also buy" and "most buy" are already reflected on sales data, customers think their product assurance is stronger than those marked with "you probably are interested" and "the most viewed". That is to say, customers consider the current recommendations as being convincing only when they are based on the information about the products for which the purchase decision is made by others (e.g., items already bought, services already accepted, or content already downloaded or subscribed). As for the products marked with "limited time sale" and "discount", a lower price always seems to be an attracting factor invoking customer's purchases and the analysis of the results also reveals this phenomenon on the lower "price level".

It is clearly shown that recommending/advocating titles of "you probably are interested" and "the most viewed" on ESHOP.com are not significantly effective on saving back its customers' removed products and repurchasing similar items. Other than "most buy", "the most viewed" might only show popularity of the items, but is not enough to convince them to buy. Products within entitled "you probably are interested" imply personal recommending items. At the current stage on ESHOP.com, customers may either not trust in the host e-retailer or in such mechanism.

\section{TIME TRANSIENT EFFECT ON PRODUCT (OR SIMILARITIES) BEING PUT BACKINTO BASKET}

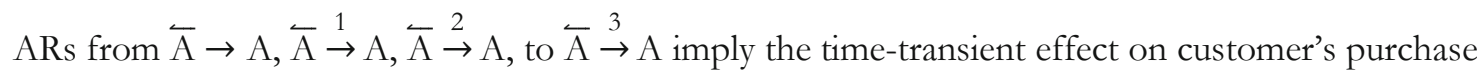
intention. The advocating/recommending effect fades over time, according to Figure 1, for all of the different effective factors. That is, the advocacy/recommendation banners show instant effectiveness on the same customer visits. As time passes, customers' impressions of these banners may become vague. In addition, compared to the products they have reconsidered, for all AR cases, the similar products are more likely to be the substitutes chosen during the same visit. However, if the abandoned products do not appear in shopping cart again, and similar products also do not appear during the same visits, it is likely that they expect to consider purchasing again at the next and subsequent 
visits and to compare them to the similar products. However, at the third visits, customers would not intend to buy either the products or similar products and the goods are completely abandoned.

Table 3 summarizes all of the t-tests or ANOVA results of the confidence differentiations for all different pre-defined ARs.

Table 3. Summaries of the confidence differentiation for all pre-defined ARs

\begin{tabular}{|c|c|c|c|c|c|c|c|c|}
\hline $\begin{array}{l}\text { p VALUE (TWO- } \\
\text { TAILED) }\end{array}$ & $\overleftarrow{\mathrm{A}} \rightarrow \mathrm{A}$ & $\overline{\mathrm{A}} \rightarrow \mathrm{s}(\mathrm{A})$ & $\overleftarrow{\mathrm{A}} \stackrel{1}{\rightarrow} \mathrm{A}$ & $\overleftarrow{\mathrm{A}} \stackrel{1}{\rightarrow} \mathrm{s}(\mathrm{A})$ & $\overleftarrow{\mathrm{A}} \stackrel{2}{\rightarrow} \mathrm{A}$ & $\overleftarrow{\mathrm{A}}^{\rightarrow} \stackrel{2}{\rightarrow} \mathrm{s}(\mathrm{A})$ & $\overleftarrow{\mathrm{A}} \stackrel{3}{\rightarrow} \mathrm{A}$ & $\overleftarrow{\mathrm{A}}^{\rightarrow} \mathrm{3} \mathrm{s}(\mathrm{A})$ \\
\hline Gender & $.01 *$ & $0.04^{*}$ & $0.00^{*}$ & 0.23 & 0.56 & 0.11 & 0.98 & 0.99 \\
\hline Price level & $.00^{*}$ & $0.00^{*}$ & $0.00^{*}$ & $0.04 *$ & 0.27 & 0.37 & 0.97 & 0.97 \\
\hline Other also buy & $.00^{*}$ & $0.00^{*}$ & 0.72 & 0.37 & 0.20 & 0.72 & 0.99 & 1.00 \\
\hline Most buy & .09 & $0.00^{*}$ & $0.00^{*}$ & $0.01 *$ & $0.01 *$ & 0.31 & 0.91 & 0.99 \\
\hline Time limit sales & $.02 *$ & $0.01 *$ & $0.00^{*}$ & $0.02 *$ & 0.07 & 0.42 & 1.00 & 1.00 \\
\hline Discount & .78 & 0.77 & 0.89 & 0.71 & 0.88 & 0.70 & 0.99 & 1.00 \\
\hline
\end{tabular}

*: significance at level 0.05 .

Female customers on ESHOP.com can be easily influenced to change their minds by the advocacy banners or to ruminate over their choices. The products with upper level prices tend to be unfavorable. That is, a customer's choice of product replacement is prone to be the substitutes with lower or medium price levels. This implies that an up-selling strategy for ESHOP.com would not be successful on such banners. Although "discount" banners still are significantly effective, from the patterns for all banners, the confidence values for the "Yes" and "No" are very close for all types of ARs. Hence, this study concludes that members on ESHOP.com may show less reflection on the "discount" advocacy banners than those with other titles.
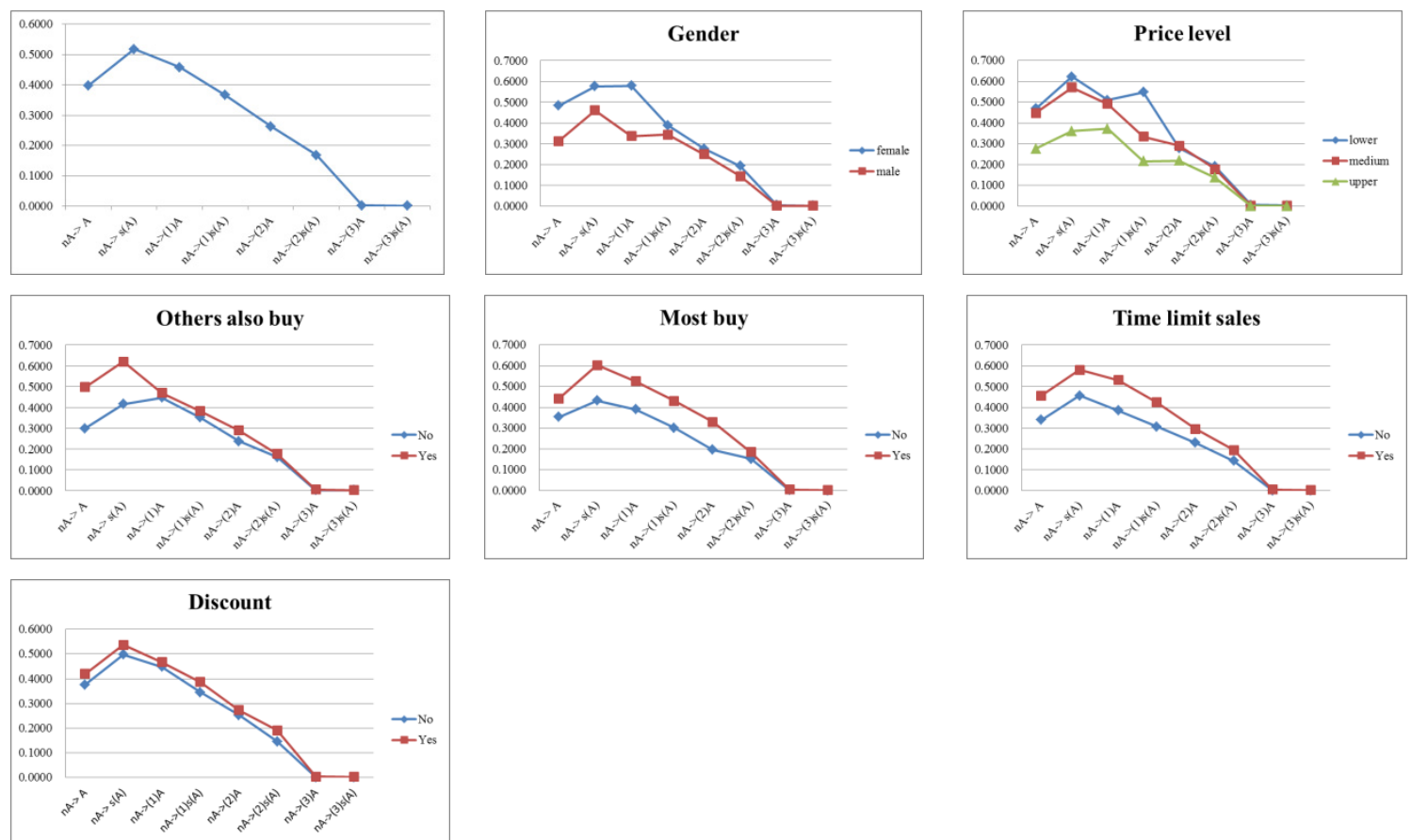

Figure 1. Confidence values for all pre-defined ARs 


\section{DISCUSSION}

The objective of this study was to use individual clickstream data and browsing behavior to determine whether or not different advocacy/recommendation banners show immediate effects on customers' decisions to abandoned products. Specifically, this study investigated whether exposure to these banners alters some of the subsequent purchasing choices a customer makes while shopping online. The analytic results give web sellers confidence that the banners to some extent, influence customers to seek out additional information and invoke them reconsider or replace their abandoned choices.

Website visitors' responses to online promotions and content offerings enable e-businesses to have a greater ability to make real-time adjustments to market segmentation models and content targeting. Marketers are able to increase the targeting accuracy of online content, messages and product offerings using e-business analytics, which provide customer knowledge by understanding their customers' purchasing behavior as revealed through basket transactions. The basket transaction is therefore treated by marketers as the most powerful piece of information for e-retailing businesses. Unfortunately, most retailers currently collect these transactions into data on only what was sold and then set them aside. In effect, what most retailers are throwing away is the documented purchasing behavior of all their customers. Customers' behavior can be gauged completely and objectively by what they buy and what they intend (or intended) to buy through the basket analysis.

Recommendations direct customers to similar products to the ones they liked. Recommender systems can perform product recommendations in a content-based manner, wherein descriptions about products (such as goods, services, and content) may be used. For example, similar customers, or customers making a purchase decision for similar products usually have a high probability to share the same purchase intention for particular types of products, so the recommender system may contribute to increased sales. An online recommendation solution in which a recommended product is selected based on a customer's behavior records in each phase of the online purchase-decision process means that the recommenders with richer content can be more effective, and thus, the conversion rate of the online decision making can be improved. A computer-implemented recommendation engine can be configured to provide selected products to the first customer according to one or more second customers' historical behavior records. The one or more second customers are users who are presented in one or more phases as having a higher decision conversion rate are influenced by the recommenders because the recommended products fit their needs better.

However, based on the finding that the recommender entitled "you probably are interested" is not effective on sales raise after products in shopping carts being abandoned. This could support the literature that customers tend to hold more positive attitudes towards the source from third parties rather than that coming directly from the sellers (Lepkowska-White, 2013) as well as that acceptance and usefulness of recommender systems provided directly from e-retailers might be gauged with online users' trust (Pu \& Chen, 2007; Wang \& Benbasat, 2007).

There are few notes to make regarding the proposed methodology in this study. First, to determine similar products, the Jaccard coefficient being adopted, attribute selection is a case-dependent design by business practitioners. Online retailers would choose necessary attributes to access product similarities. Also, in this study, a binary calibration, i.e., either attributes being matched or not between products, could be in a generalized measurement, for instance, fuzzy numbers (Zadeh, 1965). Furthermore, literature for the algorithms to determine similar products (e.g., Du \& Wang, 2014; Morozov \& Babenko, 2018; Schuh, Riesener, \& Rudolf, 2014) could be alternatively applied.

\section{CONCLUSION}

This study addressed this measurement challenge by leveraging the information from clickstream data - particularly retailing webpages browsing behavior. These data are most useful to observe the 
real-time behavior of consumers on websites and also are applied to studying click-through behavior (note that the effectiveness in this study is not gauged with click-through rates) for web banners. This study, developing a new methodology to evaluate the effectiveness of online marketing campaigns, contributes to the literature regarding data mining on online consumer behaviors and the emerging topics of e-retail recommendation.

One managerial implication is more effective adoption of advocacy/recommendation banners on eretailing websites. Lepkowska-White (2013) gave evidence that customers tend to hold more positive attitudes towards information coming from third parties rather than coming directly from the sellers. However, this study has testified to the effectiveness of advocacy/recommendation banners posted directly by an e-retailer. This is in contrast to current recommender systems, which only recommend products for which a purchase-decision was made, and are thus, based only on the information about the purchase decision making. However, products abandoned by customers on the checkout page are often reconsidered or replaced with similar ones when the webpages of products also contain advocacy banners with "the most buy" and "others also buy". For advocating/recommending purposes, these banners would save lost sales to a substantial degree. Therefore, the future application of the study findings and approach can provide better targeting of such banners on websites.

Moreover, affinity marketing focuses on finding customers for a certain product or topic, and then on offering that customer related products or information from other customers with similar interests. The implementation of this study fits with the central theme of affinity marketing, by utilizing group affiliation (either customers or products) as a means of generating a strong and credible promotional program that is specifically tailored to the individual, but is within the context of the group. Both group and individual incentives are often an integral part of the affinity programs. The methodology used in this study is technically feasible but requires that online retailers move to truly interactive websites. Since, in reality, the decision of online retailers to use banners is somewhat influenced by suppliers or supplies, possibly due to prices or inventories, the arrangement of showing banners on product pages may not truly reflect the products in terms of banners entitled "most people bought", or "most people viewed", but may only be used for promotion/sales purposes by the retailers. The website of ESHOP.com is an e-commerce platform that allows product suppliers to register products online. ESHOP.com provides the IT and payment services for the supplying partners of the products. The banner displays are a true reflection of the information given and thus, the research results are reliable and trustworthy.

Another managerial implication is the evaluation of the advocacy/recommendation banners. As expressed in Section 2, some researchers and practitioners doubt the click-through rate for gauging the success of banner usage. By using a data mining technique to find the association between removed products and restored ones in e-shoppers' shopping carts, the approach and findings of this study, which are important for e-retailing marketers, reflect the connection between the usage of banners and the personalized purchase changes in an individual customer's shopping cart. Personalization has become an important technique that allows businesses to improve both sales and service relationships with their online customers. This personalization gives e-marketers the ability to deliver real effectiveness in the use of banners.

Noted, data for the empirical study were derived from the actual customers' website clickstreams in a certain period of time and also the advocating titles were only based on the designs at the target website in Taiwan. Study findings of the effects of recommenders, therefore, limit. That is, such effectiveness is time- and case-sensible. Business practitioners and academic researchers are encouraged to apply the mining methodology to longevity studies, specific marketing campaigns of advertising and personal recommendations, and any further recommendation algorithms. Additionally, for the international e-retailers who run their websites in more than two countries, conducting culturecomparative studies are also worthwhile. Furthermore, since the recommender entitled "you probably are interested" is not effective on saving back the removed products and/or recommending simi- 
lar products instead, customer trust issue, either in the e-retailer or in the recommending mechanism, is worthy to be investigated.

\section{REFERENCES}

Aggarwal, P., \& Vaidyanathan, R. (2005). Perceived effectiveness of recommendation agent routines: Search vs experience goods. International Journal of Internet Marketing and Advertising, 2(1), 38-55. https://doi.org/10.1504/IJIMA.2005.007503

Agrawal, R., Imielinski, T., \& Swami, A. (1993). Mining association rules between sets of items in large data bases. The ACM SIGMOD Conference on Management of Data. 207-216. https://doi.org/10.1145/170036.170072

Agrawal, R., \& Srikant, R. (1994). Fast algorithms for mining association rules. Proceedings of the $20^{\text {th }}$ International Conference on Very Large Data Bases, Santiago, Chile, 487-499. https:/ / dl.acm.org/citation.cfm?id=672836

Aljukhadar, M., \& Senecal, S. (2011). Usage and success factors of commercial recommendation agents: A consumer qualitative study of MyProductAdvisor.com. Journal of Research in Interactive Marketing, 5(2/3), 130152. https://doi.org/10.1108/17505931111187776

Ansari, A. M., Essegaier, S., \& Kohli, R. (2000). Internet recommendation systems. Journal of Marketing Research, 37(3), 363-375. https://doi.org/10.1509/jmkt.37.3.363.18779

Biyalogorsky, E., Gerstner, E., \& Libai, B. (2001). Customer referral management: Optimal reward programs. Management Science. 20(1), 82-95. https://doi.org/10.1287/mksc.20.1.82.10195

Bloom, P. N., Hoeffler, S., Keller, K. L., \& Basurto Meza, C. E. (2006). How social-cause marketing affects consumer perceptions. MIT Sloan Management Review, 47(2), 49-55.

Butler, P., \& Peppard, J. (1998). Consumer purchasing on the Internet: Processes and prospects. European Management Journal, 16(5), 600-610. https://doi.org/10.1016/S0263-2373(98)00036-X

Clifford, L. (2008). Big data: How do your data grow? Nature, 455, 28-29. https://doi.org/10.1038/455028a

Constantinidea, E. (2008). The empowered customer and the digital myopia. Business Strategy Series, 9(5), 215223. https://doi.org/10.1108/17515630810906710

Courbet, D., Fourquet-Courbet, M.-P., \& Vanhuele, M. (2007). How web banner designers work: The role of Internal dialogues, self-evaluations, and implicit communication theories. Journal of Advertising Research, 47(2), 217-229. https://archivesic.ccsd.cnrs.fr/sic 00288393

Du. C., \& Wang, J. (2014). Inner product similarity search using compositional codes. arXiv:1406.4966. https://doi.org/10.1109/ICPR.2014.638

DoubleClick (2002). Full-year ad serving trends. Retrieved from www.doubleclick.net

Dreze, X., \& Hussherr, F.-X. (2003). Internet advertising: Is anybody watching? Journal of Interactive Marketing, 7(4), 8-23. https://doi.org/10.1002/dir.10063

East, R., Lomax, W., \& Narain, R. (2001). Customer tenure, recommendation and switching. Journal of Consumer Satisfaction, Dissatisfaction ad Complaining Behavior, 14, 46-54.

Ehrenberg, A., Barnard, N., Kennedy, R., \& Bloom, H. (2002). Brand advertising as creative publicity. Journal of Advertising Research, 42, 7-18. https://doi.org/10.2501/jar-42-4-7-18

Eguia, I., Lozano, S., Racero, J., \& Guerrero, F. (2011). A methodological approach for designing and sequencing product families in reconfigurable disassembly systems. Journal of Industrial Engineering and Management, 4(3), 418-435. https://doi.org/10.3926/jiem.2011.v4n3.p418-435

Geng, L., \& Hamilton, H. J. (2006). Interestingness measures for data mining: A survey. ACM Computing Surveys, 38(3) (2006). https://doi.org/10.1145/1132960.1132963

Goh, K. Y., \& Chintagunta, P. K. (2006). The effect of banner advertising on Internet purchasing. Journal of Marketing, 43(1), 98-108. https://doi.org/10.1509/jmkr.43.1.98

Gold, K. (2007). Tackling the shopping cart abandonment rate. Retrieved from www.searchmarketingstandards.com 
Goodman, C. (2014). Up close and personal. Target Marketing, 37(1), 29-30. https://doi.org/10.1016/S0262$\underline{4079(14) 62408-8}$

Han, J., \& Kamber, M. (2001). Data mining: Concepts and Techniques. Morgan Kaufmann Publishers, Waltham.

Han, J., Pei, J., \& Yin, Y. (2000). Mining frequent patterns without candidate generation. Proceedings of the ACM SIGMOD Conference on Management of Data (SIGMOD '00. ACM Press). 1-12. https://doi.org/10.1145/335191.335372

Haubl, G., \& Murray, K. B. (2006). Double agents. MIT Sloan Management Review, 47(3), 8-12.

Interactive Advertising Bureau (IAB) (2011). Retrieved from http://www.iab.net/about the $\mathrm{iab} /$ recent press releases/press release archive/press release/pr-052611

Jaccard, P. (2013). Wikipedia contributors: "Paul Jaccard”. Retrieved from http://en.wikipedia.org/wiki/Paul Jaccard

Joshua, J. V., Alao, O. D., Adebayo, A. O., Onanuga, G. A., Ehinlafa, E. O., \& Ajayi, O. E. (2016). Data mining: A book recommender system using frequent pattern algorithm. Journal of Software Engineering and Simulation, 3(3), 1-13.

Kim, D. J. (2002). Three essays on trust in business-to-consumer electronic commerce. Ph.D. dissertation: State University of New York at Buffalo. https://doi.org/10.1097/00006123-199901000-00111

Klemettinen, M., Mannila, H., Ronkainen, P., Toivonen, H., \& Verkamo, A. I. (1994). Finding interesting rules from large sets of discovered association rules. Third International Conference on Information and Knowledge Management (CIKM'94), 401-407. https://doi.org/10.1145/191246.191314

Lawrence, R. D., Almasi, G. S., Kotlyar, V., Viveros, M. S., \& Duri, S. S. (2001). Personalization of supermarket product recommendations. In Kohavi R., \& Provost F. (Eds.), Applications of data mining to electronic commerce (pp 11-32). Springer, Boston, MA. https://doi.org/10.1007/978-1-4615-1627-9 2

Lee, W., Salvatore, J. S., \& Kui, W. M. (2002). Algorithms for mining system audit data. In Lin T. Y., Yao Y. Y., \& Zadeh L. A. (Eds.), Data Mining, Rough Sets and Granular Computing (166-189). Studies in Fuzziness and Soft Computing, 95. Physica: Heidelberg. https://doi.org/10.1007/978-3-7908-1791-1 8

Lepkowska-White, E. (2013). Are they listening? Designing online recommendations for today's consumers. Journal of Research in Interactive Marketing, 7(3), 182-200. https://doi.org/10.1108/JRIM-07-2012-0027

Lohtia, R., Donthu, N., \& Hershberger, E. K. (2003). The impact of content and design elements on banner advertising click-through rates. Journal of Advertising Research, 43(4), 410-418. https://doi.org/10.2501/JAR$\underline{43-4-410-418}$

Manchanda, P., Dube, J.-P., Goh, Y., \& Chintagunta, P. K. (2006). The effect of banner advertising on Internet purchasing. Journal of Marketing Research, 43(1), 98-108. https://doi.org/10.1509/jmkr.43.1.98

Morozov, S., \& Babenko, A. (2018). Non-metric similarity graphs for maximum inner product search. The $32^{\text {nd }}$ Conference on Neural Information Processing Systems (NeurIPS 2018), Montréal, Canada. https://doi.org/10.1117/12.23395

Nasco, S., \& Bruner, G. (2008). Comparing consumer responses to advertising and non-advertising mobile communications. Psychology and Marketing, 25(8), 822-838. https://doi.org/10.1002/mar.20241

Ochi, P., Rao, S., Takayama, L., \& Nass, C. (2010). Predictors of user perceptions of web recommender systems: how the basis for generating experience and search product recommendations affect user responses. International Journal of Human-Computer Studies, 68(8), 472-482. https://doi.org/10.1016/j.ijhcs.2009.10.005

Osadchiy, T., Poliakov, I., Olivier, P., Rowland, M., \& Foster, E. (2019). Recommender system based on pairwise association rules. Expert Systems with Applications, 115, 535-542. https://doi.org/10.1016/i.eswa.2018.07.077

Pagnani, M. (2004). Determinants of adoption of third generation mobile multimedia services. Journal of Interactive Marketing, 18(3), 46-59. https://doi.org/10.1002/dir.20011

Piatetsky-Shapiro, G. (1991). Discovery, analysis, and presentation of strong rules. Knowledge Discovery in Databases, 229-238. 
Pu, P., \& Chen, L. (2007). Trust-inspiring explanation interfaces for recommender systems. Knowledge-Based Systems, 20(6), 542-556. https://doi.org/10.1016/j.knosys.2007.04.004

Rosen, D. L., \& Olshavsky, R. W. (1987). A protocol analysis of brand choice strategies involving recommendations. Journal of Consumer Research, 14(3), 440-444. https://doi.org/10.1086/209126

Rutz, O. J., \& Bucklin, R. E. (2012). Does banner advertising affect browsing for brands? Clickstream choice model says yes, for some. Quantitative Marketing Economics, 10(2), 231-257. https://doi.org/10.1007/s11129$\underline{011-9114-3}$

Schuh, G., Riesener, M., \& Rudolf, S. (2014). Identifying preferable product variants using similarity analysis. Procedia CIRP, 20, 38-43. https://doi.org/10.1016/i.procir.2014.05.029

Senecal, S., \& Nantel, J. (2004). The influence of online product recommendations on consumers' online choices. Journal of Retailing, 80(2), 159-169. https://doi.org/10.1016/j.jretai.2004.04.001

Tan, P., Kumar, V., \& Srivastava, J. (2002). Selecting the right interestingness measure for association patterns. KDD '02: Proceedings of the eighth ACM SIGKDD International Conference on Knowledge Discovery and Data Mining (pp. 32-41). https://doi.org/10.1145/775052.775053

Theresia, W. A., \& Noranita, B. (2012). Apriori application to pattern profile creditor relationships with credit ceiling in rural bank. ICISBC '11 Proceedings of the 1st International Conference on Information Systems for Business Competitiveness (pp. 75-80), Semarang. Retrieved from http://eprints.undip.ac.id/36074/1/Theresia Widji.pdf

Varzaneh, H. H., Neysiani, B. S., Ziafat, H., \& Soltani, N. (2018). Recommendation systems based on association rule mining for a target object by evolutionary algorithms, Emerging Science Journal, 2(2), 100-107. https://doi.org/10.28991/esj-2018-01133

Volk, F. A. (2001). Internet users' attitudes and e-commerce behaviors. Ph.D. dissertation: Wichita State University. https://doi.org/10.1145/505103.505122

Wang, W., \& Benbasat, I. (2007). Recommendation agents for electronic commerce: Effects of explanation facilities on trusting beliefs. Journal of Management Information Systems, 23(4), 217-246. https://doi.org/10.2753/MIS0742-1222230410

Weathers, D., Sharma, S., \& Wood, S. L. (2007). Effects of online communication practices on consumer perceptions of performance uncertainty for search and experience goods. Journal of Retailing, 83(4), 393-401. https://doi.org/10.1016/j.jretai.2007.03.009

West, P. M., Ariely, D., Bellman, S., Bradlow, E., Huber, J., Johnson, E., Kahn, B. Little, J., \& Schkade, D. (1999). Agents to the rescue? Marketing Letters, 10(3), 285-300. https://doi.org/10.1016/B978-0-7506-8566$\underline{5.50029-7}$

Yao, X.-L., \& Shu, H.-Y. (2009). Study on value-added service in mobile telecom based on association rules. SNPD 09 Proceedings of the 10th International Conference on Software Engineering: Artificial Intelligences, Networking and Parallel/ Distributed Computing (pp. 116-119). Daegu, South Korea. https://doi.org/10.1109/SNPD.2009.38

Yeh, H. (2014). Forecasting personal shopping behavior. Pensee Journal, 76(10), 389-399. https://doi.org/10.24297/ijct.v13i2.2907

Yeu, M., Yoon, H.-S., Taylor, C. R., \& Lee, D.-H. (2013). Are banner advertisements in online games effective? Journal of Advertising, 42(2-3), 241-250. https://doi.org/10.1080/00913367.2013.774604

Zadeh, L. A. (1965). Fuzzy sets. Information and control. Information and Control, 8(3), 338-353. https://doi.org/10.1016/S0019-9958(65)90241-X

Zagoruiko, N. G., Borisova, I. A., Kutnenko, O. A., \& Dyubanov, V. V. (2013). A construction of a compressed description of description of data using a function of rival similarity. Journal of Applied and Industrial Mathematics, 7(2), 275-286. https://doi.org/10.1134/S199047891302018X

Zahir, S. (2002). Designing a knowledge-based interface for intelligent shopping agents. Journal of Computer Information Systems, 43(1), 31-41. https://doi.org/10.1023/A:1008717005478 
Zhang, Y. (2009). Association rule mining in cooperative research. Thesis of Science and Industrial Engineering: University of Missouri-Columbia. https://doi.org/10.23956/ijarcsse.v7i8.58

\section{BIOGRAPHIES}

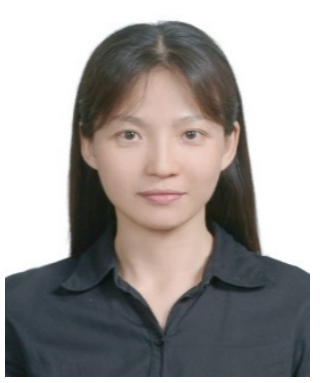

Hsiaoping Yeh is an Associate Professor in the Department of Marketing \& Logistics Management at National Kaohsiung University of Science and Technology in Taiwan. She holds a doctorate in Industrial Engineering from the University of Wisconsin-Madison. Her current research interests focus on customer relationship management, service innovation, and knowledge management. She can be contacted at hpyeh2000@,nkust.edu.tw.

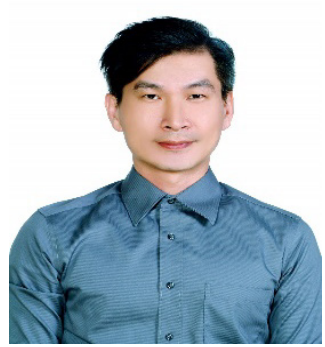

Fenghung Kuo is a Doctoral student in the Department of Marketing \& Logistics Management at National Kaohsiung University of Science and Technology in Taiwan. His current research interests focus on electronic commerce, customer relationship management, and supply chain management. He can be contacted at $\underline{0428902 @ \text {,nkust.edu.tw. }}$ 